\title{
We welcome a new Editor for New Diffraction Data
}

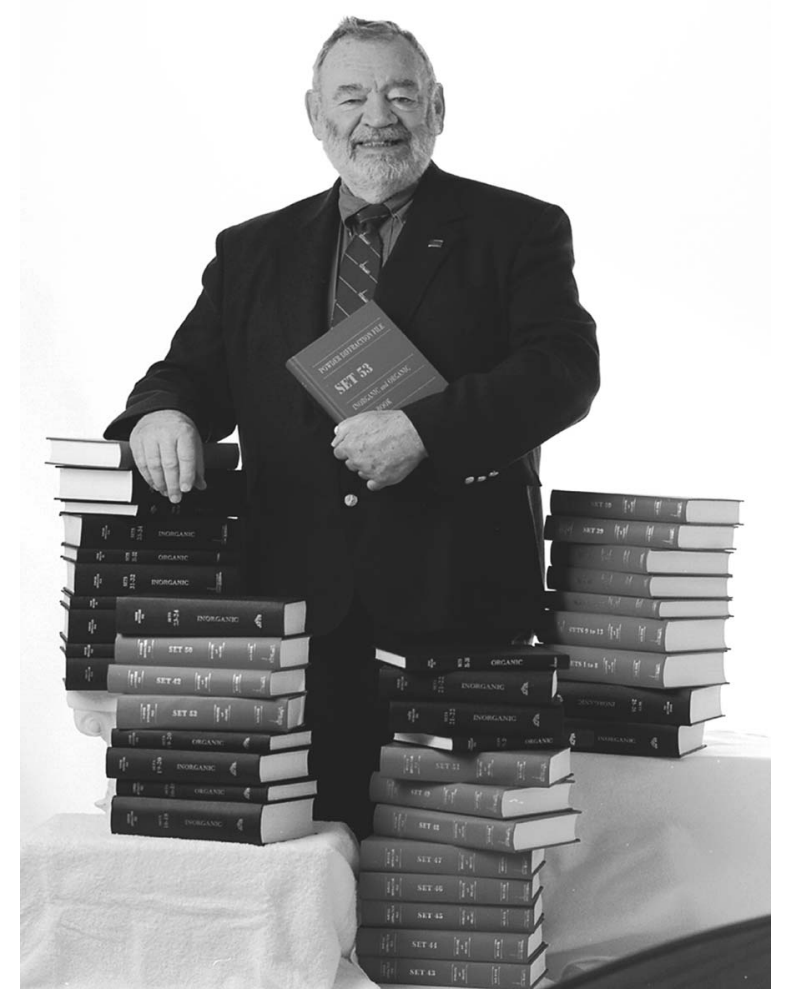

We are delighted also to announce that Frank McClune has accepted our invitation to serve as an Editor for the New Diffraction Data Section of Power Diffraction. Frank brings long experience to the journal in the editing of powder diffraction data as he has been served as the Editor-in-Chief of the Powder Diffraction File (PDF) for the past 20 years. Frank nurtured the transition of the PDF from cards and books into PDF-4 family of relational database products available on CD-ROM and DVD. The PDF has grown tremendously in size and technical capability due to Frank's coordination with editorial task teams, cooperating database organizations, and the development of an extensive and rigorous editorial process. He was elected an ICDD Fellow in 2000 and designated a Distinguished Fellow at the Annual Meeting of ICDD members in 2003 for his outstanding contributions to the PDF.

Ting C. Huang Editor-in-Chief 